\title{
Update of immunomodulatory therapy for inflammatory bowel disease
}

\author{
CHARLES N BERNSTEIN MD FRCPC
}

CN BERNSTEIN. Update of immunomodulatory therapy for inflammatory bowel disease. Can J Gastroenterol 1994;8(7):413-416. For several decades corticosteroids were the only potent immunomodulatory agents effective and available for active inflammatory bowel disease (IBD). The past decade has seen an enhanced knowledge of the immune response in IBD and a better understanding of how common immunomodulatory agents work. Furthermore, more specific mediators of the abnormal immune response have been identified, so that therapy can be more targeted. Purine analogues have proven efficacy in achieving and maintaining remission in both Crohn's disease and ulcerative colitis. Methotrexate has proven efficacy in active Crohn's disease. Both of these classes of drugs requires weeks to months of treatment before any benefit is seen. Intravenous cyclosporine is efficacious in acute severe ulcerative colitis and can settle active disease within days of administration. It is unclear whether oral cyclosporine offers any advantage at maintaining remission, once achieved. Oral cyclosporine in Crohn's disease has been proven to be ineffective at either achieving or maintaining remission; however, intravenous cyclosporine in Crohn's disease has not been rigorously tested. Newer immunomodulatory agents have been designed for specific targets, and in particular monoclonal antibodies that block the effects of interleukin-1, tumour necrosis factor-alpha and the $\mathrm{T}$ cell receptor are available for clinical trials. We are in an era of expanding therapeutic approaches to these diseases, including the refined use of readily available agents, the development of newer, more targeted agents and a broader understanding of how agents may be effectively used simultaneously or sequentially.

Key Words: Crohn's disease, Immunomodulation, Inflammatory bowel disease, Treatment, Ulcerative colitis

\section{Mise à jour sur le traitement immunomodulateur dans les maladies inflammatoires de l'intestin}

RÉSUMÉ : Depuis quelques décennies, les corticostéroïdes étaient les seuls agents immunomodulateurs puissants, efficaces offerts pour traiter les maladies inflammatoires de l'intestin (MII). La dernière décennie a permis de beaucoup

voir page suivante

Section of Gastroenterology, Health Sciences Centre, Winnipeg, Manitoba

Correspondence: Dr Charles N Bernstein, Section of Gastroenterology, GB443 Health Sciences Centre, 820 Sherbrook Street, Winnipeg, Manitoba R3A IR9. Telephone (204) 787-1434, Fax (204) 787-4826

Received for publication June 20, 1994. Accepted July 13, 1994
W HILE THE CAUSE(S) OF INFLAMmatory bowel disease (IBD) ulcerative colitis and Crohn's disease remains unclear, advances in our understanding of the mechanisms and mediators involved in the pathogenesis has provided a sound rationale for the therapeutic use of immunomodulatory drugs, and has led to novel therapeutic approaches. The basis of immunomodulatory therapy in both Crohn's disease and ulcerative colitis is as follows: there is general agreement that the immune system mediates the tissue damage in these disorders; and, while environmental factors including infectious agents might be disease triggers in genetically susceptible individuals, there is no convincing evidence for any ongoing infection in either condition (1).

This review discusses the available immunomodulatory therapies that are typically considered in the treatment of patients with IBD when corticosteroids and other conventional management have failed.

\section{PURINE ANALOGUES}

Azathioprine is the S-imidazole precursor of 6-mercaptopurine (6-MP) and was developed with the hope that the active moiety would be released more slowly than 6-MP. These drugs act at crucial steps in B and T cell activation, blocking gene activation and proliferation. However, their exact mechanism of action in IBD is unknown. The two drugs probably have similar efficacy 
mieux comprendre la réponse immunologique et le rôle des agents immunomodulateurs d'usage courant dans les MII. De plus, des médiateurs plus spécifiques de la réponse immunitaire anormale ont été identifiés, de sorte que le traitement peut être mieux ciblé. Les antipurines ont prouvé leur efficacité à produire et maintenir une rémission dans la maladie de Crohn et dans la colite ulcéreuse. Le méthotrexate s'est révélé efficace dans la maladie de Crohn évolutive. Ces deux classes de médicaments doivent être administrées durant des semaines, voire des mois avant qu'un bienfait ne soit observé. La cyclosporine intraveineuse est efficace dans la colite ulcéreuse grave aiguë et peut ralentir la maladie évolutive en quelques jours. On ignore si la cyclosporine orale offre quelqu'avantage dans le maintien de la rémission une fois qu'elle est installée. La cyclosporine orale dans la maladie de Crohn s'est révélée inefficace à amener ou à maintenir la rémission. Toutefois, la cyclosporine intraveineuse dans la maladie de Crohn n'a pas fait l'objet d'études rigoureuses. Des agents immunomodulateurs plus récents ont été conçus en fonction de cibles spécifiques, notamment les anticorps monoclonaux qui inhibent l'effet de l'interleukine 1 , du facteur alpha de nécrose tumorale et du récepteur des cellules T sont utilisés dans des essais cliniques. Nous sommes à une époque où les approches thérapeutiques se multiplient pour traiter ces maladies, y compris le recours plus judicieux à des agents déjà existants, la création de nouveaux produits mieux ciblés et une meilleure compréhension de la façon dont ces agents peuvent être utilisés efficacement simultanément ou séquentiellement.

and toxicity; however, there is a paucity of comparative data.

Early controversy about the use of purine analogues in IBD was related primarily to negative results found in some early trials including the National Cooperative Crohn's Disease Study (2). Limitations in the design of early studies, particularly the failure to account for the slow onset of clinical efficacy of purine analogues, were subsequently recognized. These agents require a median of three months before clinical efficacy is apparent. This implies that they are not likely to be useful for acutely ill patients and that other medications such as corticosteroids should not be withdrawn while initiating this form of immunomodulatory therapy.

The most convincing evidence for the efficacy of 6-MP in the treatment of active Crohn's disease was a landmark study by Present et al (2) in 1980. This double-blind, placebo controlled study over a period of two years avoided the limitations of earlier studies. 6-MP proved to be effective compared with placebo in terms of improvement of clinical status, reduction in concurrent corticosteroids use and closure of fistulas. A recently presented meta-analysis on the use of purine analogues has confirmed their efficacy in active disease
(3). While the role of purine analogues in ulcerative colitis is less rigorously defined, there is evidence for therapeutic efficacy. These agents offer a steroid-sparing effect and a reasonable alternative when surgery is undesirable or risky. Studies have also shown that azathioprine in ulcerative colitis and azathioprine and 6-MP in Crohn's disease are useful agents in maintaining remission.

The main toxicity associated with purine analogue therapy is myelosuppression, although it is typically mild (4). Complete blood counts should be checked monthly, although profound myelosuppression is rare with low doses and rigorous blood count monitoring. There is a $3 \%$ incidence of allergic reactions, including pancreatitis. A recent study from St Mark's Hospital in England revealed no overall increased incidence of noncolorectal cancer in patients with IBD using purine analogues (5). However, the data for use longer than five years suggested a possible increased risk of cancer and, thus, ongoing treatment after a lengthy remission should be readdressed. Recent data suggest that after lengthy remissions (greater than four years), relapse rates upon purine analogue therapy withdrawal may be as low as $10 \%$ at up to three years (6).

\section{CYCLOSPORINE}

The impact of cyclosporine on the outcome of organ transplantation has been revolutionary. In the past several years it has also been tested in many autoimmune diseases, usually in more refractory cases. Its role in IBD is still being defined.

The action of cyclosporine is lymphocyte specific, noncytotoxic and reversible, and it avoids the myelotoxic side effects of agents like 6-MP. It is thought to act on $\mathrm{T}$ cell function and proliferation, mostly through inhibition of interleukin-2 (IL-2) gene transcription and thus, diminution of its release. IL-2 is a cytokine, or cell messenger, that directs the recruitment and expansion of effector $\mathrm{T}$ cells and $\mathrm{T}$ cell dependent immunological events. Recently, mice rendered incapable of producing IL-2 by a knock-out gene technique have proven to develop an inflammatory colitis. This has raised questions regarding the specific site of immunomodulation by cyclosporine in IBD.

In contrast to other immunosuppressants, the required dose of cyclosporine is highly variable, requires close monitoring and blood levels are an essential guide. In this respect, an understanding of the pharmacokinetics of cyclosporine is important. Oral absorption of cyclosporine is slow and incomplete, and takes place in the small intestine. Cyclosporine metabolites are concentrated in the bile and alterations in bile flow can, therefore, influence cyclosporine levels. There is little renal excretion and dose adjustments are not necessary in chronic renal failure or in patients on hemodialysis (the drug is also not removed by dialysis). Drugs that affect the cytochrome P-450 system will have important effects on cyclosporine levels.

Cyclosporine has been shown to benefit approximately $70 \%$ of patients with active severe ulcerative colitis who are on the threshold of colectomy. This has been confirmed in a recent randomized, placebo controlled study (7). An advantage of cyclosporine is that when it is effective, its effects are evident within two weeks of initiating therapy. One problem with cyclospor- 
ine is the high relapse rate once the drug is withdrawn. In ulcerative colitis the toxicity of cyclosporine must be weighed against the ability to be cured of the disease with total colectomy. This agent can be used in patients who refuse surgery or in patients mentally unprepared for surgery and its attendant risks. Long term data regarding how many patients are truly spared colectomy within one year of initiating cyclosporine therapy are lacking. Cyclosporine might best be used as a bridge to long term purine analogue therapy.

In a placebo controlled, doubleblind trial in Crohn's disease, Brynskov et al (8) used oral cyclosporine A (5 to $7.5 \mathrm{mg} / \mathrm{kg} /$ day) in patients with active and resistant disease. At the end of three months, $59 \%$ of patients improved by using a clinical scale versus $32 \%$ of patients receiving placebo $(\mathrm{P}=0.032)$. The improvement clinically, however, was mild with a significant relapse rate after drug withdrawal. A Canadian multicentre, randomized, placebo controlled trial in patients with active Crohn's disease and in patients with Crohn's disease in remission revealed that oral cyclosporine (starting dose $2.5 \mathrm{mg} / \mathrm{kg}$ ) was no more efficacious than placebo (9). This important study has proven that as an oral adjunct in inactive or moderately active Crohn's disease, oral cyclosporine has no role. However, neither of these published studies in Crohn's disease has addressed the use of higher dose intravenous cyclosporine. Ironically, intravenous cyclosporine has been studied in ulcerative colitis where small bowel absorption of lipid soluble agents should be preserved, and only oral cyclosporine has been studied in Crohn's disease where absorption of the drug may be variable through a diseased small bowel. Colonic tissue cyclosporine levels are 10 times higher in normal subjects after intravenous dosing compared with oral dosing (10).

The variable small bowel absorption in Crohn's disease requires that the clinician heed drug levels. In acutely ill patients, particularly those with Crohn's disease, initiation of therapy by the intravenous route is preferable and the appropriate starting dose is
$4 \mathrm{mg} / \mathrm{kg} /$ day. Once efficacy has been clearly demonstrated, intravenous cyclosporine can be switched to oral cyclosporine by doubling the required intravenous dose. Drug doses should then be adjusted to therapeutic blood levels, which vary according to the method of measurement done at the individual centres.

Hypertrichosis, gingival hyperplasia, tremors and paresthesias are the most common side effects. Seizures after intravenous cyclosporine administration have been reported and may be a particular risk in patients with hypocholesterolemia (9). Nephrotoxicity may occur in an acute or chronic form and is particularly more common in patients taking nephrotoxic drugs concurrently. In more than $90 \%$ of patients, renal dysfunction will be reversible upon discontinuing the drug. However, irreversible diffuse interstitial fibrosis after prolonged use has been reported. Other reversible metabolic problems seen with cyclosporine use include hyperkalemia, hyperuricemia and hepatotoxicity. There is a concern that the incidence of lymphoproliferative disorders and other malignancies is increased in patients using cyclosporine.

\section{METHOTREXATE}

Methotrexate is a folic acid antagonist which has an inhibitory effect on proliferating cells, while sparing resting cells. In contrast to cyclosporine, monitoring blood levels is not an important clinical consideration with methotrexate. At oral doses of less than 30 $\mathrm{mg} / \mathrm{m}^{2}$, methotrexate is nearly completely absorbed from the gastrointestinal tract.

Over the past two decades methotrexate has gained widespread use in the treatment of several chronic inflammatory conditions. Preliminary reports of open use of methotrexate in Crohn's disease have been quite promising. The relapse rate is likely too high in patients with ulcerative colitis to make this a reasonable option for these patients. A recent Canadian multicentre randomized, placebo controlled trial of weekly intramuscular methotrexate (25 mg) in patients with Crohn's disease revealed a significant benefit at inducing remission over the 16 weeks of the trial (11). Methotrexate is effective in approximately $40 \%$ of patients.

Methotrexate should be considered as a second option after first considering a purine analogue in patients with Crohn's disease who have failed to achieve remission after a prolonged therapeutic course or who have failed to withdraw from corticosteroids.

Toxicity with methotrexate is mild in general, and includes transient serum transaminase elevations, leukopenia and rarely hypersensitivity pneumonitis. Pre-methotrexate percutaneous liver biopsies in IBD patients are unnecessary unless they have $a b$ normal liver tests.

\section{HYDROXYCHLOROQUINE}

Chloroquine and hydroxychloroquine, traditionally used as antimalarials, also have a role in the management of some chronic inflammatory disorders including systemic lupus and rheumatoid arthritis. These agents interfere with cellular antigen presentation by raising the $\mathrm{pH}$ within intracellular acid vesicles. Altered antigen presentation by intestinal epithelial cells can affect the type of immune effector cell that is stimulated (ie, $\mathrm{T}$ suppressor versus $\mathrm{T}$ helper cells).

Clinically, hydroxychloroquine is favoured over chloroquine because of an improved safety profile particularly in relation to the potential for ocular toxicity. Preliminary uncontrolled studies of chloroquine and hydroxychloroquine have been promising in patients with ulcerative colitis but disappointing in patients with Crohn's disease. Although hydroxychloroquine (400 mg/day for six weeks) did not have a statistically significant therapeutic effect compared with placebo in patients with ulcerative colitis, a substantial subset of patients appeared to undergo a striking remission. Another trial with a higher dose of hydroxychloroquine ( $800 \mathrm{mg} /$ day) and for a longer period of treatment (eight weeks) is now underway at the Mount Sinai Medical Center in New York. Its main advantage is its ease of administration and lack of serious toxicity. This agent would be a second choice in patients with therapy- 
resistant ulcerative colitis, after first considering purine analogue therapy.

\section{NEWER AGENTS}

FK506 and rapamycin are macrolide antibiotics that have a similar action to cyclosporine. These agents have been useful in solid organ transplantation and only recently have been considered for therapeutic studies in IBD. Newer corticosteroids are also becoming available that will have the same immunomodulatory effect and anti-inflammatory action as prednisone but with reduced systemic toxicity. Budesonide is one such corticosteroid that is available in enema form and studies with an oral agent have proven its efficacy in Crohn's disease. Other corticosteroid agents including deflazacort are currently under investigation in patients with Crohn's disease.

Monoclonal antibodies: As knowledge of cytokines and immune mediators improves, the cloning of the molecules and their receptors has made the development of very specific therapies possible. An increasing variety of monoclonal antibodies that recognizes specific $T$ cell surface determinants, complement receptors and adhesion molecule receptors have been used therapeutically in experimental animal models of autoimmune disease and IBD. Pilot trials with monoclonal antibodies

\section{REFERENCES}

1. Bernstein CN, Shanahan F. Immunomodulatory therapy in inflammatory bowel disease. In: Targan S, Shanahan F, eds. Inflammatory Bowel Disease; From Bench to Bedside. Baltimore: Williams and Wilkins, 1994:503-23.

2. Present DH, Korelitz BI, Wisch N, Glass JL, Sachar DB, Pasternack BS. Treatment of Crohn's disease with 6-mercaptopurine. A long term randomized double blind study. N Engl J Med 1980;302:981-7.

3. Pearson DC, May GR, Sutherland LR. Azathioprine and 6-mercaptopurine in Crohn's disease: A meta-analysis. Gastroenterology 1994;106:A1045.

4. Bernstein CN, Artinian L, Anton PA, Shanahan F. Low dose 6-mercaptopurine in inflammatory bowel disease is associated with minimal hematological toxicity. Dig Dis Sci 1994;39:1638-41. directed against $\mathrm{T}$ cell surface antigen have reported promising results in some patients with Crohn's disease.

Cytokine modulation: There are a number of endogenous factors that can antagonize the actions of IL-1. IL-1 is an important early mediator of the immunoinflammatory response. Recently, an antagonist to the IL-1 receptor has been identified and has been found to be endogenously produced. The current view on the role of IL-1 in the immune response of IBD is that there is a balance maintained between IL-1 and the IL-1 receptor antagonist that keeps the intestinal inflammatory response in check. IBD is associated with an imbalance that favours an abundance of IL-1 relative to the antagonist (12). Currently, therapeutic trials with IL-1 receptor antagonist are underway in ulcerative colitis. Tumour necrosis factor-alpha is another cytokine that has an important role in the immunoinflammatory response. Monoclonal antibodies that can 'mop up' circulating tumour necrosis factor-alpha will be available soon for therapeutic testing in IBD.

\section{CONCLUSIONS}

For the complicated or corticosteroid-dependent IBD patient, the clinician should be comfortable with the use of purine analogues, like azathio-

5. Connell WR, Kamm MA, Dickson M, Balkwill AM, Ritchie JK, LennardJones JE. Long-term neoplasia risk after azathioprine treatment in inflammatory bowel disease. Lancet 1994:343:1249-52.

6. Bouhnik Y, Scemama G, Lemann M, et al. Effect of immunosuppressive therapy withdrawal on the course of Crohn's disease (CD) in patients successfully maintained in prolonged remission using azathioprine (AZP) or 6-mercaptopurine (6-MP).

Gastroenterology 1994;106:A655.

7. Lichtiger S, Present DH, Kornbluth A, et al. Cyclosporine in severe ulcerative colitis refractory to steroid therapy. N Engl J Med 1994;330:1841-5.

8. Brynskov J, Freund L, Rasmussen SN A placebo controlled, double-blind randomized trial of cyclosporine therapy in active chronic Crohn's disease. N Engl J Med 1989;321:845-50. prine or 6-MP. For patients who require further medical therapy, cyclosporine, methotrexate and hydroxychloroquine are attractive alternatives. There are few nonsurgical options to offer acutely ill corticosteroid-resistant Crohn's disease patients, therefore cyclosoporine is a tempting alternative as its therapeutic onset is seen within days. Oral cyclosporine has proven to be mostly ineffective in this setting, but higher dose intravenous cyclosporine has yet to be tested in a rigorous controlled study. At present, despite the widespread availability of cyclosporine and methotrexate, these agents are best reserved for clinicians who are comfortable with their administration and toxicity.

The future will not only bring more critical data on the use of current immunomodulatory agents but also data on the use of newer immunomodulators that presently are finding their places in the fields of organ transplantation and animal models of autoimmune disease. With new technologies and a better understanding of immune interactions, 'designer' drugs can be made with very specific targets. We have entered the threshold of an exciting era in the field of immunomodulation. The agents developed will allow more treatment options, as well as insight into the abnormal immune regulation in IBD.

9. Feagan BG, McDonald JWD, Rochon J, et al, and the Canadian Crohn's

Relapse Prevention Trial Investigators. Low-dose cyclosporine for the treatment of Crohn's disease. $\mathrm{N}$ Engl ] Med 1994;330:1846-51.

10. Sandborn WJ, Strong RM, Forland SC, Chase RE, Cutler RE. The pharmacokinetics and colonic tissue concentrations of cyclosporine after iv, oral, and enema administration. J Clin Pharmacol 1991;31:76-80.

11. The North American Crohn's Disease Study Group Investigators. A multicentre trial of methotrexate (MTX) treatment for chronically active Crohn's disease. Gastroenterology 1994;106:A745.

12. McCall RD, Haskill S, Zimmerman EM, Lund PK, Thompson RC, Sartor RB. Tissue interleukin-1 and interleukin-1 receptor antagonist expression in enterocolitis in resistant and susceptible rats. Gastroenterology 1994;106:960-72. 


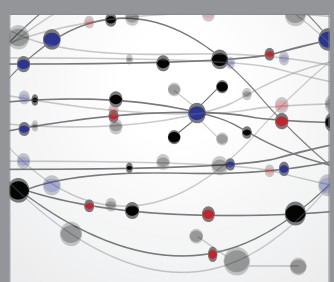

The Scientific World Journal
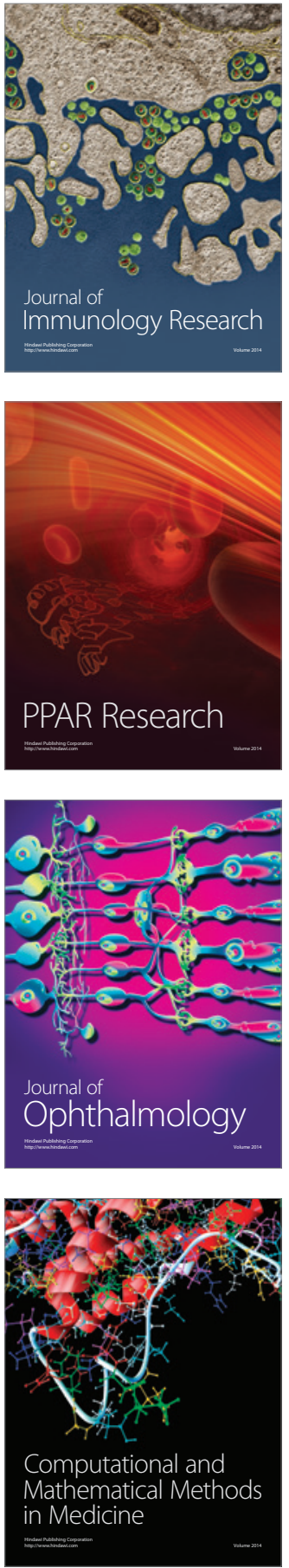

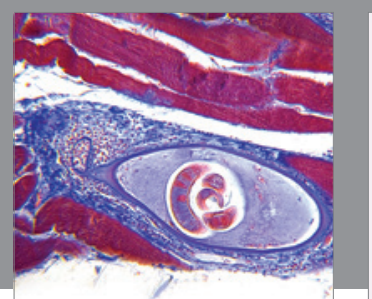

Gastroenterology Research and Practice

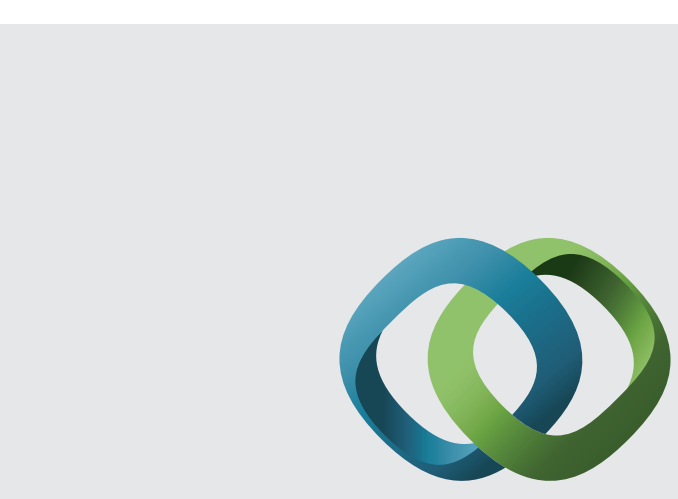

\section{Hindawi}

Submit your manuscripts at

http://www.hindawi.com
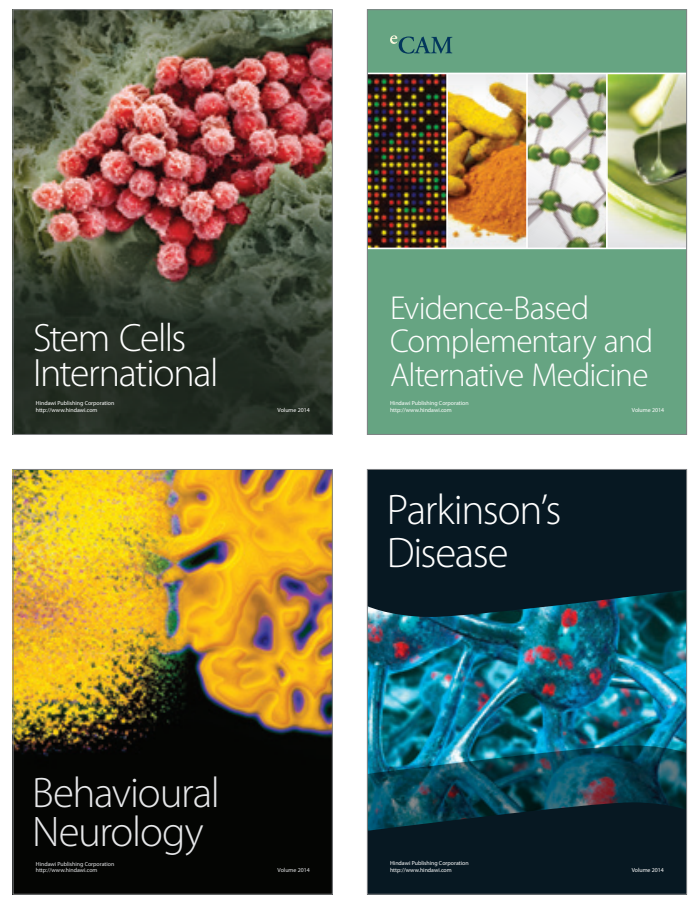
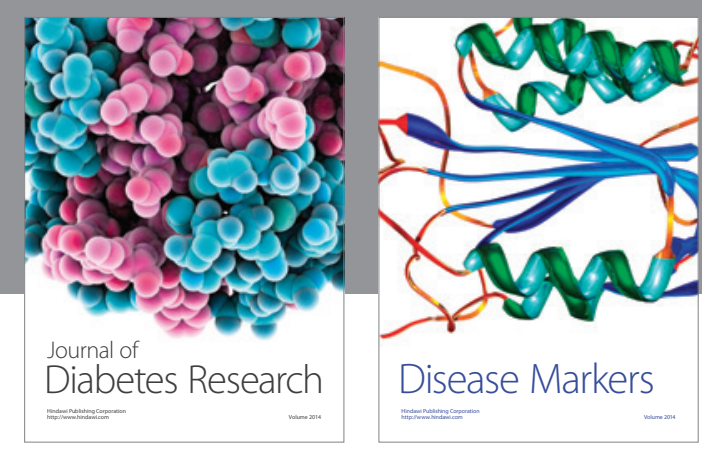

Disease Markers
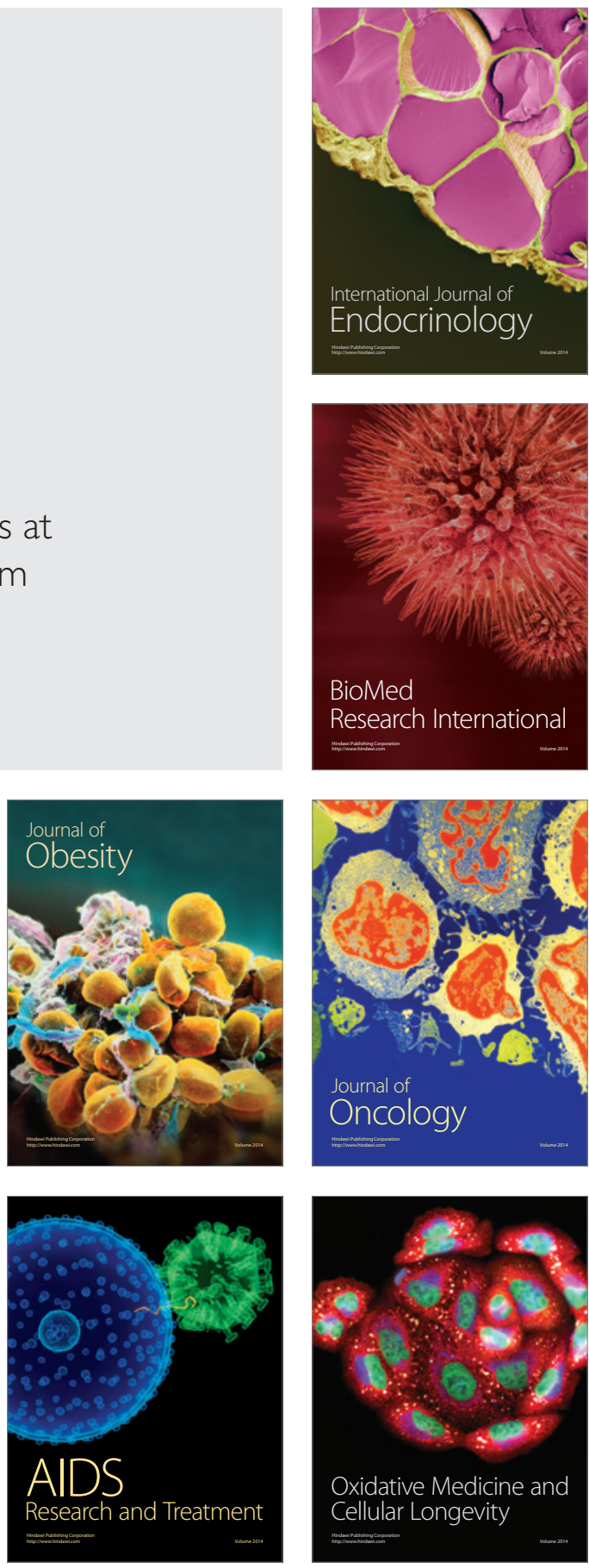